\title{
GLUCOSE MONITORING FOR TYPE 1 DIABETES MELLITUS IN JUNIOR RHYTHMIC GYMNASTICS - A CASE REPORT
}

\author{
Aura BOTA ${ }^{1}$, Mariana MEZEI ${ }^{2}$, Mihaela VLĂICULESCU ${ }^{3}$, Constanța URZEALĂ $^{1 *}$ \\ ${ }^{1}$ National University of Physical Education and Sport, Faculty of Physical Education and Sport, Bucharest, \\ Romania \\ ${ }^{2}$ Politehnica University, Faculty of Medical Engineering, Bucharest, Romania \\ ${ }^{3}$ Outpatient Diabetes Clinic "DiabNutriMed" Telemedicine Centre, Bucharest, Romania; \\ Support for Diabetes Association, Bucharest, Romania \\ *Corresponding author: constanta.urzeala@unefs.ro
}

https://doi.org/10.35189/dpeskj.2021.60.4.1

\begin{abstract}
The main challenge in managing type 1 diabetes mellitus is to achieve the glycaemic targets, especially when top-level athletes are involved. The present paper aims at identifying the daily continuous glycaemic oscillations that occur on a regular basis during rhythmic gymnastics training sessions. This is a case report of a 12-year-old junior rhythmic gymnast diagnosed with type 1 diabetes mellitus, with 6 years of experience in sport. Her glycaemic records were available for analysis through the FreeStyle Libre glucose monitoring sensor. The investigation took place in Bucharest between March 30 and April 26, 2021. During this time, the gymnast attended training sessions, provided that her glycaemic values allowed her to perform physical exercise. Data resulting from the LibreView specific software were correlated with the exercise parameters. From the diabetes management standpoint, it was emphasised the distribution of glycaemic values (in range, above and below the target zone) in bi-monthly and daily reports to identify the glucose profiles on training and non-training days. Depending on glycaemic oscillations, the coach adjusted in real time the training load for the athlete so that hypo-and hyperglycaemic episodes are avoided. Glucose monitoring could safely establish risk-free time intervals for both health and training purposes.
\end{abstract}

Keywords: flash glucose monitoring, sports performance, diabetes management.

\section{Introduction}

Managing juvenile Type 1 Diabetes Mellitus (T1DM) has been an international research topic due to its increased incidence and repercussions upon public health. Worldwide estimates reveal that more than 98,000 children under 15 years are diagnosed every year with T1DM. Globally, there are almost 600,900 children suffering from this chronic disease (Patterson et al., 2019). Although the incidence rate widely varies across countries, it is known that, in Europe, Finland is situated first, with more than 40 cases per 100,000/year (Santi et al., 2019), while in Asia, India recorded the highest value with 0.1-8 per 100,000/ year (Chiang et al., 2014).

Diagnosed on the basis of blood sugar measurements and specific symptoms such as impaired state of health, weight loss, polydipsia or polyuria, T1DM is an autoimmune condition of uncertain aetiology, requiring lifelong insulin therapy, glucose monitoring, nutritional education, physical exercise and psycho-social care (Ziegler \& Neu, 2018). The autoimmune character of this disease is proven by the specific auto-antibodies that attack the islet cells, producing their destruction (Atkinson \& Eisenbarth, 2001). Moreover, this autoimmune dysfunction has the potential to produce other organ-specific or nonspecific autoimmune diseases such as thyroid, celiac and gastric conditions (Kakleas et al., 2015). 
Usually, once diagnosed, the child is immediately referred to a diabetologist with paediatric experience or to a paediatrician with diabetes experience. The specialist will establish treatment goals regarding the target $\mathrm{HbA1c}$, namely the best indicator of the metabolic control in T1DM, expressing the average blood glucose concentration in the last 23 months. Concretely, the standards refer to less than $7.5 \%$ or even less than $7 \%$ for HbA1c, when telemedicine devices are used (Miller et al., 2015). Besides HbA1c, another widely used relevant parameter in diabetes management is the time in normoglycemia, namely Time in Range (TIR), which is $70-180 \mathrm{mg} / \mathrm{dl}$, the equivalent of $3.9-8.9 \mathrm{mmol} / \mathrm{l}$. Specialists state that a glucose level above $250 \mathrm{mg} / \mathrm{dl}$ prior to exercise should postpone any physical activity unless urine ketones are checked. If the level exceeds $300 \mathrm{mg} / \mathrm{dl}$, physical exercise is completely banned (Shugart et al., 2010).

In order to accurately identify daily glycaemia oscillations, children and adolescents have to measure their blood sugar 5-6 times per day or even more (Ziegler et al., 2011). According to these values, prandial analogues and basal insulin will cover mealtimes and adjust high glucose values in an individualised pattern (Cemeroglu et al., 2013). Traditionally, insulin therapy is delivered either intravenous, in ketoacidosis treatment, or using an insulin pen.

Latest technologies developed in the area of telemedicine have provided more accurate and less invasive procedures for insulin therapy delivery and optimal glucose control. Thus, insulin pump therapy consists in the administration of treatment according to the needs of the child, including boluses for mealtimes and adjustments of high glucose levels. From the circadian rhythm perspective, insulin secretion is lower at night and higher during morning, which is known as "the dawn phenomenon" (Porcellati et al., 2013). In this context, cohort studies show that insulin pumps lead to an overall metabolic improvement through less frequent hypoglycaemic episodes and prevention of hyperglycaemia during morning (Karges et al., 2017). The interstitial glucose concentration is measured every 3-5 minutes through continuous glucose monitoring (CGM) systems by means of a subcutaneous sensor, the values being transmitted to a receiver. Another technical solution is represented by flash glucose monitoring (FGM) that allows to detect glycaemic values only when the receiver scans the sensor in its proximity (Ly et al., 2013). According to numerous studies (Ziegler et al., 2016; Ly et al., 2013; Karges et al., 2017), CGM systems allow children to access bloodless sugar measurements to minimise the frequency of hypoglycaemic episodes, thus becoming less dependent on their parents and more likely to fully enjoy a good quality of life.

Medical treatment should be complemented in the long term by the child's commitment to an active lifestyle, including regular physical exercise as part of the diabetes education. This endeavour should be supported by a multidisciplinary team consisting of physicians, parents, educators and peers in order to formulate consensual goals for proper diabetes management.

Studies (Yardley at al., 2013; Marliss \& Vranic, 2002) emphasise that physical exercise may lead to either hypo- or hyperglycaemia, depending on the training load and the hormone regulatory particularities. Very often, fear of exercise-induced hypoglycaemia perceived by both children and parents is the main roadblock to participation in regular physical activity (Roberts et al., 2020). This occurs especially when T1DM children are not appropriately monitored, in terms of glucose and insulin adjustments, prior, during and post-exercise (Roberts et al., 2017). 
Although fear of hypoglycaemia (FOH) is the main barrier to performing physical activity, excessive FOH can lead to opposite negative metabolic consequences such as hyperglycaemia, low glycaemic control and maladaptation to an autonomous lifestyle (Johnson et al., 2013; Gonder-Frederick et al., 2011). A cross-sectional study (Beraki et al., 2014) based on a diabetes quality registry in Sweden aimed at assessing possible associations between physical exercise and HbA1c within a large group of 7-18-year-old patients. The most relevant results emphasised the following aspects: the least physically active participants had higher mean HbA1c levels than the most physically active ones; a negative correlation was found between HbA1c and physical activity for both genders and age groups, except for girls aged 7-10 years; boys were slightly more active compared to girls.

Based on these arguments, practising high-level sports is not considered an unrealistic option, provided that the whole training process meets the requirements for risk-free participation of the T1DM child. This goal becomes attainable through long-term cooperation between athletes, parents, technical and medical staff. According to evidence, the sports activities performed by T1DM children and adolescents range from leisure physical activities to Olympic participation (Harris \& White, 2012). Either way, exercise is based on anaerobic or aerobic energy sources (Riddell \& Iscoe, 2006). Specifically, most gymnastics events access the anaerobic lactic energy pathway, which is characterised by high intensities, explosive power from ATP and CP, specific endurance due to glycolysis, production of lactic acid and duration of maximum 90 seconds, according to the time limit of the routines (Sands et al., 2001). Nonetheless, each training session or competition event requires many hours, which triggers aerobic energy systems as well. Overall, exercise is determined by complex physiological factors such as insulin, glucagon, cortisol and catecholamines and growth hormones, their ratio depending on the exercise intensity and duration (Camacho et al., 2005). Thus, in low-moderate intensity, the energy resource is mostly represented by plasmaderived free fat acids, while during heavy exercise, the carbohydrate use may reach 1-1.5 $\mathrm{g} / \mathrm{kg} /$ hour in adolescents with diabetes (Riddell et al., 2000). Within an intensive workout, catecholamines are triggered, which increases the release of liver glucose, free fat acids and the ketone levels while diminishing the use of glucose by muscles; consequently, anaerobic exercise leads to hyperglycaemia for T1DM athletes, even under insulin therapy (Ridel et al., 2017).

As research has brought evidence of the metabolic control in diabetes pathology, authors have proven the possibility to engage T1DM children and adolescents in sports training due to both the physiological and psychological benefits perceived by competitors (Harris \& White, 2012). In this context, the sports literature emphasises numerous T1DM athletes competing in football, basketball, handball, cycling, soccer, ice hockey, rowing, softball, swimming, tennis, taekwondo, winter sports, etc.

This study aimed at presenting a way to integrate glycaemia monitoring for a T1DM rhythmic gymnast within the training process. Based on a case report, this investigation started from the following research questions: what is the glucose profile that allows the gymnast to perform during the training session? are there optimal measures to be taken by the coach in real time so that the risk of hypo- or hyperglycaemia is avoided? 


\section{Case report}

\section{Participant}

The gymnast analysed in this study was a 14-year-old girl with 9 years of experience in rhythmic gymnastics. Her best sports results included several national titles with the team as well as finals qualifications in individual events. In October 2018, she was diagnosed with T1DM, being provided with a glycaemia monitoring system from the onset of the disease. Her diabetes management included 17 units basal insulin and 8 to 12 units prandial insulin administered before or after meals, depending on her glucose values, along with a nutritional diet and physical activity. The patient used to correct hyperglycaemic spikes with 2 units of rapid analogue. She attended 8 training sessions of 2 hours 30 min each during the analysed period.

In the last 3 years, her diabetes was closely monitored by a diabetologist, including regular HbA1c checks that gave information about her average blood glucose levels over a 3month period. At present, she uses a FreeStyle Libre sensor-based glucose monitoring device. The research protocol met the requirements of the Declaration of Helsinki regarding human participants. Her parents signed the informed consent. Data were anonymised.

\section{Procedure}

The gymnast's weight and height were assessed using a digital scale and a standard stadiometer. Body mass index (BMI) was also determined and analysed on percentile charts.

A one-month period of glucose monitoring was trimmed from the FreeStyle Libre continuous streaming data and analysed in conjunction with the sports training content. This device allows glucose monitoring on the gymnast's reader by scanning her sensor with a specific LibreView application.

The FreeStyle Libre is a FGM system comprising a sensor attached to the upper part of the arm, which continuously captures the glucose concentration within the subcutaneous interstitial fluid and displays a new value every 5 minutes by means of a thin filament puncturing the skin; a reader that scans the sensors allows data collection. Every 14 days, the sensor needs to be replaced, being a consumable item. The FGM is considered as a hybrid between the finger prick blood glucose measurements and the CGM systems (diaTribe Foundation, 2021; Naaraayan et al., 2018). Overall, the advantage of using the FGM for a child resides in a lower number of daily finger pricks and thus a less traumatising T1DM management. Nonetheless, when there are suspicions about the glucose level readings, finger pricks are required because accurate data are mandatory. Three types of information are available via FGM: the current glucose level, the trend of glucose oscillations, the last 8 hours of recordings. Data are processed with the LibreView application that provides periodical ambulatory glucose profile (AGP) curves as well as AGP reports. These included four glucose ranges highlighted in different colours, namely low glucose level $<70 \mathrm{mg} / \mathrm{dl}$ (red), target zone level 70-180 mg/dl (green), above target level 180-250 mg/dl (yellow) and very high glucose levels $>250 \mathrm{mg} / \mathrm{dl}$ (orange). Data from the AGP reports are processed by the LibreView software, glycaemia values being processed and converted in different graphs, 
as if occurring in a single day. A relevant parameter provided by the software is the Glucose Management Indicator (GMI), which is more or less an equivalent of the HbA1c.

For this research, two AGP reports were analysed per 14 days, from March 30 to April 26, highlighting the differences between training and non-training days, in terms of glucose control. During this period, the training contents, the gymnast's symptoms and the counter measures applied by the coach were also analysed. In order to identify the exercise loads producing hyper- or hypoglycaemia, observational files were completed during the training sessions. In this respect, a Zephyr device was available for assessing punctual heart rate and thus the corresponding exercise intensities. The point values of the heart rate in different moments of the training sessions were extracted separately from the HRV analysis, which is the main parameter assessed using the Zephyr device.

\section{Results}

\section{Anthropometric measurements}

The gymnast weighted $58 \mathrm{~kg}$ and her height was $160 \mathrm{~cm}$. The calculated BMI was 22.65 $\mathrm{hg} / \mathrm{m}^{2}$ corresponding to healthy weight category. Regarding the growth percentile charts, her BMI fell between 75 and 85 percentiles. The girl experienced menarche at 13 years old.

\section{Glucose monitoring synthesis}

Figure 1 shows the monthly summary of average glucose levels, the number of daily scans and the extreme (low or high) values, if present. One can notice that, in the 13 days of the analysed period, glycaemia recorded values under $250 \mathrm{mg} / \mathrm{dl}$. In the rest of the days, glucose levels exceeded $250 \mathrm{mg} / \mathrm{dl}$, with the pick values highlighted in orange. No hypoglycaemia events were recorded during this month. In terms of number of scans per day, the gymnast checked her glucose sensor less than 10 times/day, only in 6 of the 28 days of monitoring, proving good compliance with this task. 


\begin{tabular}{|c|c|c|c|c|c|c|c|}
\hline \multirow{3}{*}{ 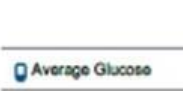 } & Monday & Tuesday & Wochesday & Thursday & Finday & Saturday & Sundry \\
\hline & ᄂ & 30 & 31 & 1 & 2 & 3 & 4 \\
\hline & & High & & 200 moit & 189 mats & 190 molt & 211 movi \\
\hline o scanaliom & & $\begin{array}{c}256 \mathrm{mg} / \mathrm{dL} \\
17\end{array}$ & 16 & $13 \div$ & $3=$ & $10 ?$ & $15=$ \\
\hline \multirow[t]{13}{*}{ min Low Glucoso Events } & & & & & & & \\
\hline & 8 & 6 & \begin{tabular}{l|l} 
& 7 \\
\end{tabular} & 8 & 9 & \begin{tabular}{l|l}
10 \\
\end{tabular} & \begin{tabular}{l|l} 
High & 11
\end{tabular} \\
\hline & 248 mojal & 148 mods & 257 mola. & 188 modi. & 162 mold. & 239 mojat & 265 moid. \\
\hline & $43 \odot$ & $44 \odot$ & $20 ?$ & $41 \%$ & $15 \bullet$ & $11 \odot$ & $5 \otimes$ \\
\hline & 12 & 13 & 14 & \begin{tabular}{|l|l|} 
& 15 \\
\end{tabular} & 16 & 17 & \\
\hline & 238 mola & 253 mods & 258 mold. & 277 mols. & 234 mols. & 266 mo/a & 276 mola. \\
\hline & $35 \%$ & $40 \%$ & $20 \%$ & $17 \%$ & $16 \bullet$ & $10 \%$ & $8 \%$ \\
\hline & $\begin{array}{ll}\text { Hoh } & 19 \\
\end{array}$ & \begin{tabular}{l|l|} 
Hes & 20 \\
\end{tabular} & 21 & Hoh 22 & 23 & \begin{tabular}{l|l} 
Hinh & 24 \\
\end{tabular} & High 25 \\
\hline & 338 moit & 307 mgish & 247 mole. & 303 molst. & 237 mola. & 361 mola & 282 mgicl. \\
\hline & $9 \%$ & $13 \%$ & $10 ?$ & $49 \%$ & $12{ }^{\circ}$ & $3 \%$ & $7 \%$ \\
\hline & & 27 & 28 & 29 & 30 & & \\
\hline & $\begin{array}{l}\mathrm{Hos} \\
296 \text { mogal }\end{array}$ & & & & & & \\
\hline & $12=$ & & & & & & \\
\hline & & & & & & & \\
\hline
\end{tabular}

Figure 1. Monthly summary (March 30 - April 26)

The glucose average value for the first 14 days was $217 \mathrm{mg} / \mathrm{dl}$, while the similar parameter for the second period was $280 \mathrm{mg} / \mathrm{dl}$. In terms of GMI, the gymnast recorded a value of $8.5 \%$ for the first 14 days and a value of $10 \%$ for the second period.

Figure 2 indicates relevant data for diabetes management regarding the glucose levels with reference to the target range and their duration in the first 14 days of monitoring. The gymnast succeeded to stay in the target range only $32 \%$. The time spent in very high levels was $31 \%$, the time spent in high levels was $37 \%$ and no time was spent in low or very low glycaemia values. (Figure 2.a) In the next 14 days, the gymnast managed to stay in the target range only $13 \%$ of the total time. The time spent in very high levels was $63 \%$, while the time spent in high levels was $24 \%$. No time was spent in low or very low values. (Figure 2.b)

LibreView

LibreView

TIME IN RANGES

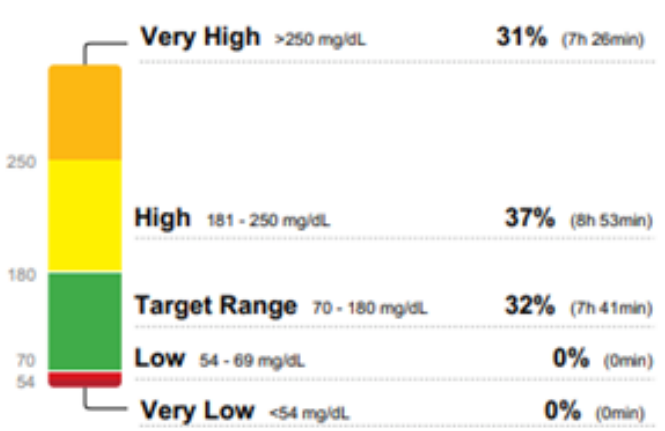

Figure 2.a. AGP report for March 30 - April 12

\section{TIME IN RANGES}

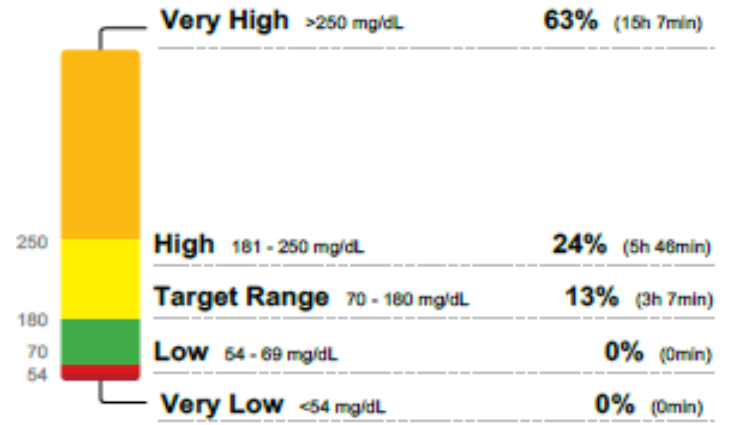

Figure 2.b. AGP report for April 13 - 26 
The AGPs illustrated in Figure 3 and Figure 4 give relevant data about both the median as a statistical cue for the recorded range of values and the trends of hypo- or hyperglycaemia. The software provides a statistical analysis for the measures of central tendency (median and mean) and the inter-quartile range (IQR) variability as shown in the figures below. The gymnast's data are analysed according to reference values incorporated in a percentile system. Therefore, the median value differs depending on the moment of the day and falls within the $50^{\text {th }}$ percentile, which is situated between the inter-quartile range. This IQR characterises the variability of value distribution between the $75^{\text {th }}$ and the $25^{\text {th }}$ percentile. Fifty percent of glucose values fall within the inter-quartile range, $25 \%$ of them fall above the $75^{\text {th }}$ percentile, while the rest fall below the $25^{\text {th }}$ percentile. In the first 14 -day report, the median had lower values between 3 and 6 a.m. (within the target range), which progressively raised, reaching the highest values between 9 a.m. and 2 p.m. The median curve decreased until 5 p.m. and recorded increased values again between 7 and 11 p.m. (Figure 3)

\section{AMBULATORY GLUCOSE PROFILE (AGP)}

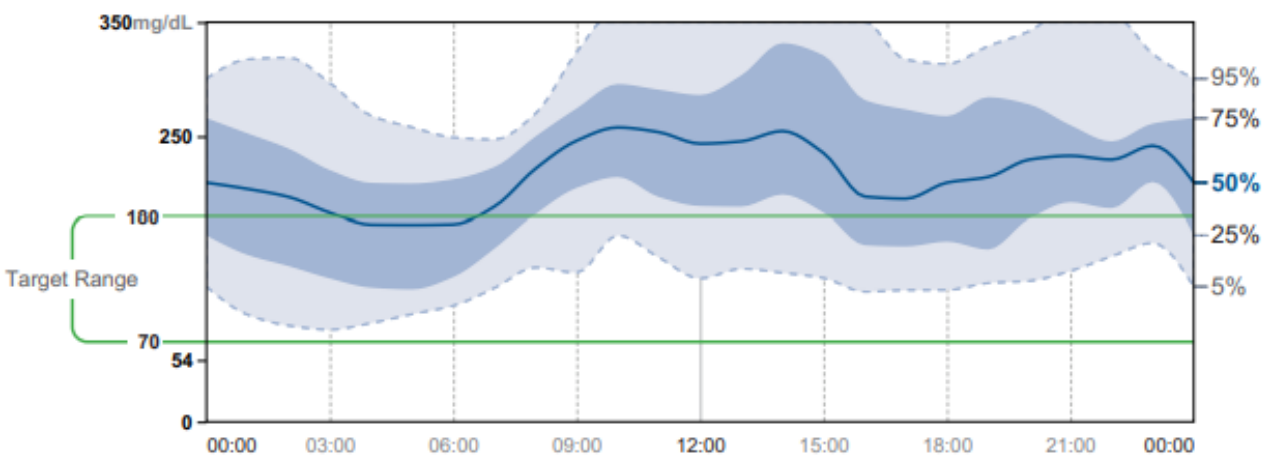

Figure 3. AGP curves for March 30 - April 12

In the next 14 days, the median had lower values between 4 and 7 a.m., which progressively raised, reaching a pick value at 11 a.m., followed by a small decrease until 1 p.m. Afterwards, the values described a high plateau with small glycaemia oscillations until 12 p.m. All median values exceeded the target range, falling within $250-300 \mathrm{mg} / \mathrm{dl}$. (Figure 4) All these data show poor metabolic control. 


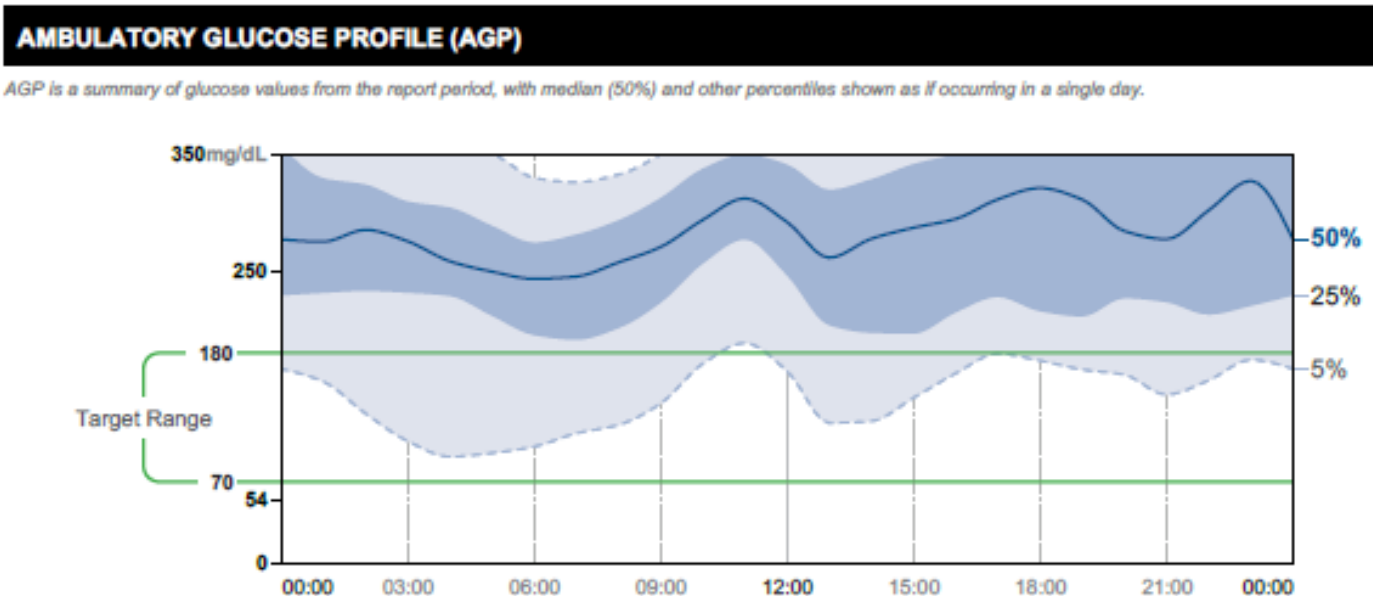

Figure 4. AGP curves for April 13 - 26

The following daily logs emphasise the scanned values during two training days with a very different glucose profile and thus with repercussions upon the training content. In both situations, the training sessions began at 11 a.m. and ended at 1.30 p.m.

Figure 5 shows that the gymnast started the first analysed training with a glucose value of $173 \mathrm{mg} / \mathrm{dl}$. Consecutive scans revealed glucose levels within the target range throughout all training sessions, the lowest value being $117 \mathrm{mg} / \mathrm{dl}$ and the highest value, $157 \mathrm{mg} / \mathrm{dl}$.

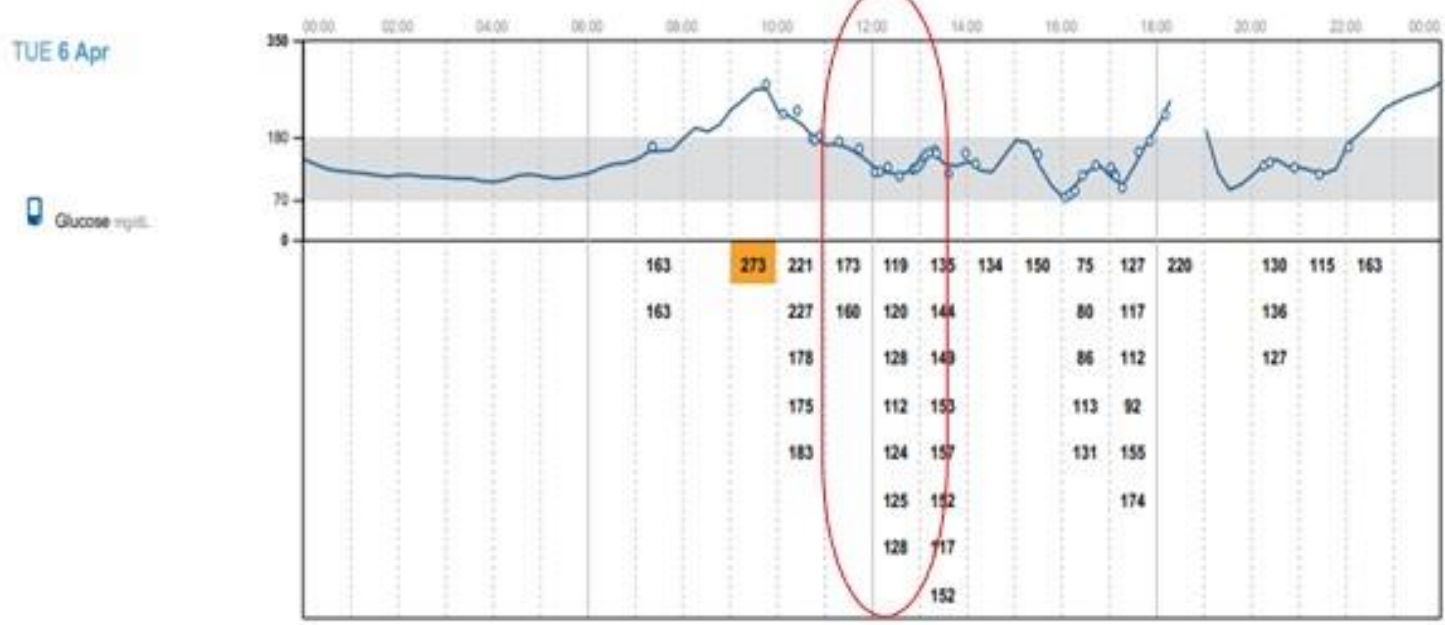

Figure 5. First training session recording

The second training session included in this case report exhibited a totally different glycaemia profile compared to the first lesson analysed (Figure 6). Due to a basal glycaemia value of $281 \mathrm{mg} / \mathrm{dl}$ at the beginning of the session, the gymnast was unable to fulfil the training tasks. Multiple scans revealed a hyperglycaemia status during the whole training sequences. Out of the 26 glucose measurements taken during the session, only 6 exhibited values that normally allow the gymnast to perform physical exercise. The rest of the values exceeding this limit exposed the gymnast to ketosis, and thus the coach decided to interrupt. 


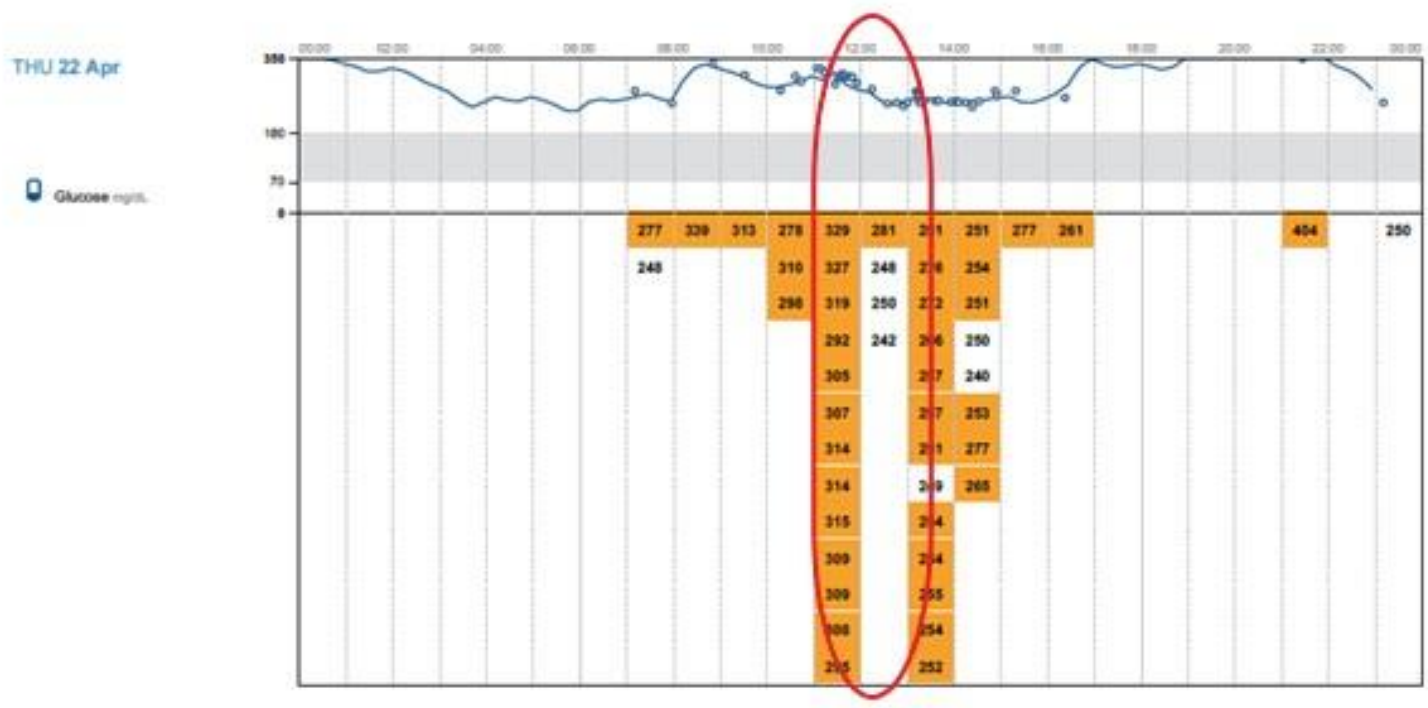

Figure 6. Second training session recording

\section{Training content analysis related to glucose oscillations}

Certain synchronised aspects related to the training load and its consequences on glucose values during the training session performed on April 6 are presented in Table 1.

Table 1. Training content analysis and glucose oscillations

\begin{tabular}{|c|c|c|c|c|}
\hline Training contents & Duration & $\begin{array}{l}\text { Average HR (beats } \\
\text { per minute) }\end{array}$ & $\begin{array}{c}\text { Glucose level } \\
\mathrm{mg} / \mathrm{dl}\end{array}$ & Carbohydrate intake \\
\hline Warm-up & $47 \mathrm{~min}$ & 116 & 173 & 0 \\
\hline - dynamic exercises & $3 \min$ & 158 & 173 & 0 \\
\hline - analytical exercises & $5 \mathrm{~min}$ & 136 & $173-160$ & 0 \\
\hline $\begin{array}{l}\text { without displacement } \\
-\quad \text { ballistic exercises } \\
\text { using the ballet barre }\end{array}$ & $10 \mathrm{~min}$ & 135 & 160 & 0 \\
\hline - splits & $15 \mathrm{~min}$ & 124 & $119-120$ & $+50 \mathrm{ml}$ orange juice \\
\hline - technical jumps & $4 \min$ & 172 & 128 & 0 \\
\hline - pirouettes & $10 \mathrm{~min}$ & 139 & 112 & $+50 \mathrm{ml}$ orange juice \\
\hline $\begin{array}{l}\text { - Specific } \\
\text { warm-up: ball }\end{array}$ & $20 \mathrm{~min}$ & 147 & $112-124$ & 0 \\
\hline - Half-routines ball & $10 \mathrm{~min}$ & 153 & $124-125$ & 0 \\
\hline Break & $10 \mathrm{~min}$ & 134 & 125 & 0 \\
\hline $\begin{array}{ll}\text { - } & \text { Whole } \\
& \text { routines: ball }\end{array}$ & $1 \mathrm{~min} 30 \mathrm{sec}$ & 161 & 128 & 0 \\
\hline break & $10 \mathrm{~min}$ & 138 & 135 & 0 \\
\hline - Whole routines: ball & $1 \mathrm{~min} 30 \mathrm{sec}$ & 174 & 144 & 0 \\
\hline - Break & $10 \mathrm{~min}$ & 129 & 149 & 0 \\
\hline - element reps & $10 \mathrm{~min}$ & 147 & 153 & 0 \\
\hline - Physical preparation & $20 \mathrm{~min}$ & 145 & 157 & 0 \\
\hline - Cool down & $10 \mathrm{~min}$ & 105 & 152 & 0 \\
\hline
\end{tabular}

According to the American College of Sports Medicine (Paternostro Bayles \& Swank, 2018), the exercise intensity can be analysed according to the five heart rate zones and the individual maximal heart rate. As shown in Table 1, the gymnast had an average HR of 144 
beats per minute (bpm) but also relevant variations depending on the sequences of the lesson. Specifically, she started the warm-up with a HR value of $116 \mathrm{bpm}$, which increased up to 158 bpm after the dynamic exercises, thus entering the heavy intensity effort zone. During analytical exercises without displacement, the HR decreased up to $136 \mathrm{bpm}$, corresponding to the moderate effort zone.

Ballistic exercises were performed in the same effort zone, followed by split flexibility exercises that lowered the parameter up to $124 \mathrm{bpm}$, corresponding to the light intensity zone. The dynamic sequence of technical jumps raised the HR to an average of $172 \mathrm{bpm}$, namely up to the very heavy intensity zone. Pirouette repetitions brought the HR to $139 \mathrm{bpm}$, in the moderate effort zone. The use of apparatus combined with body elements during the ballspecific warm-up raised the HR to $147 \mathrm{bpm}$, corresponding to the heavy effort zone. The two half routines were performed by the gymnast within the heavy effort zone, with $153 \mathrm{bpm}$. As expected, the two ball routines led to highest average heart rates (161 bpm and $174 \mathrm{bpm}$ ), which were consistent with the very heavy effort zone. During the breaks between the routines, the incomplete recovery lowered the HR values up $138 \mathrm{bpm}$ and $129 \mathrm{bpm}$, respectively. The final part of the training session where strength exercises were performed for 20 minutes led to an increase in HR up to $145 \mathrm{bpm}$, corresponding to the moderate intensity zone. The cool-down lasted 10 minutes during which the HR lowered to $105 \mathrm{bpm}$.

During the lesson, following the multiple glycaemia scans, there were two moments when the gymnast needed carbohydrate intake due to the level of glucose delivered by the FreeStyle sensor - $119 \mathrm{mg} / \mathrm{dl}$ and $112 \mathrm{mg} / \mathrm{dl}$. The recorded glycaemia values required no training content adjustments from the coach, the glucose level falling within the target range. The gymnast did not experience relevant symptoms of hypoglycaemia.

\section{Discussion}

Analysis of the monthly summary regarding glycaemia values lead to the idea that the gymnast has not managed to find proper metabolic control, which is probably related to the puberty stage characteristics. Actually, studies have stressed the importance of tackling diabetes challenges in child development (Streisand \& Monaghan, 2014) in order to prevent hypo- or hyperglycaemia events.

As a consequence, most of the days included in the report exhibited hyperglycaemia values and insufficient time spent in the range, namely almost $22 \%$ of the total period compared to the guideline reference, which is $70 \%$ (Battelino et al., 2019). With respect to the glycaemia management indicator, the gymnast's values exceeded the reference value of $7 \%$ during the monitored period, this proving once again her low ability to keep glycaemia values in the target range, especially in this critical developmental stage.

This case report has revealed that the participant is predominantly hyperglycaemic, even though her biggest concern is related to the constant fear of hypoglycaemia. This primary concern could be explained by the fact that the symptoms in hyperglycaemia events are not perceived by the child with the same intensity as the hypoglycaemia values. The number of scans per day could probably reflect the same fear of hypoglycaemia. Thus, the child is likely to develop specific severe medical complications in the long term (Katsarou et al., 2017). 
Very often, the gymnast had difficulty managing the glucose homeostasis, which exposed her to compromise the training sessions and lose her preparation level. Under these circumstances, her training objectives were adjusted by the coach to her present capabilities. Despite the T1DM, studies have revealed that high-level athletes can embark in sports training with normal loads as long as their blood glucose is properly controlled (Shugart et al., 2010).

Glucose values monitored from the first lesson were perceived by the gymnast as threatening for a possible hypoglycaemia event, but even though, these levels were in the target range. Therefore, she usually had carbohydrate intakes to maintain the level at the upper range limit. This tendency is clearly acknowledged in the literature for training sessions longer than one hour, the amount of carbs depending on the exercise intensity (Grimm et al., 2004).

Also, glycaemia during training was not necessarily influenced by the exercise intensity, as we supposed. Obviously, further measurements and monitoring are needed to address a possible statistical correlation between glycaemia and specific training load.

On the other hand, glycaemia values in the second lesson, which were noticed by the coach on the receiver of the glucose sensor, as well as the gymnast's symptoms, led to the common attempt to adjust the training load and initially engage in exercise. Still, the glycaemia control was impossible to achieve despite the long resting breaks, so the training session had to be ended.

In short, this case report has demonstrated that performing a training session necessarily requires from the very beginning a glycaemia value within the target range, which gives some space for this parameter to slightly oscillate without putting the gymnast in danger. In the long run, the $\mathrm{H} 1 \mathrm{AbC}$ value should be around 7\%, this medical cue illustrating good diabetes management and thus the athlete's capability to perform.

\section{Limitations}

The main limitation of this study was the length of the monitored period, which precluded drawing general assertions.

No previous data regarding the gymnast's glycaemia values were taken into consideration due to the difficulties reported by the family to access the LibreView application.

\section{Conclusion}

Medical records and glucose monitoring reports have emphasised that the participant's clinical condition clearly requires adjustments in diabetes management. This is a mandatory intervention for the gymnast to overcome glycaemia oscillations triggered by the puberty stage.

Conducting a training lesson with a T1DM athlete is a true challenge for any coach in terms of being aware of the specific characteristics of this metabolic disorder and adjusting in real time the training content so that a balance between the training objectives and the health status should be achieved in the long term. This strategy should be convergent with insulin therapy, nutritional recommendations and a lifelong health education. 
Although physical exercise has often proven to be beneficial for diabetes management, glucose control is essential for initiating or continuing risk-free sports training.

On a positive note, the presence of T1DM in children and youth should not hinder their quality of life and prevent them from fully enjoying sports training and competitions, provided that a joint effort of the child's family, diabetologist, coach, educators and peers is available.

\section{Authors' Contributions}

All authors have equally contributed to this paper and should be considered as main authors.

\section{Acknowledgement}

Authors would like to address sincere thanks to the gymnast and her family for their cooperation during this research.

\section{References}

Atkinson, M. A., \& Eisenbarth, G. S. (2001). Type 1 diabetes: New perspectives on disease pathogenesis and treatment. Lancet (London, England), 358(9277), 221-229. https://doi.org/10.1016/S0140-6736(01)05415-0

Battelino, T., Danne, T., Bergenstal, R. M., Amiel, S. A., Beck, R., Biester, T., Bosi, E., Buckingham, B. A., Cefalu, W. T., Close, K. L., Cobelli, C., Dassau, E., DeVries, J. H., Donaghue, K. C., Dovc, K., Doyle III, F. J., Garg, S., Grunberger, G., Heller, S., Heinemann, L., Hirsch. I. B., ... Phillip. M. (2019). Clinical targets for continuous glucose monitoring data interpretation: Recommendations from the international consensus on time in range. Diabetes Care, 42(8), 1593-1603. https://doi.org/10.2337/dci19-0028

Beraki, A., Magnuson, A., Särnblad, S., Åman, J., \& Samuelsson, U. (2014). Increase in physical activity is associated with lower HbA1c levels in children and adolescents with type 1 diabetes: Results from a cross-sectional study based on the Swedish Pediatric Diabetes Quality Registry (SWEDIABKIDS). Diabetes Research and Clinical Practice, 105(1), 119-125. https://doi.org/10.1016/j.diabres.2014.01.029

Camacho, R. C., Galassetti, P., Davis, S. N., \& Wasserman, D. H. (2005). Glucoregulation during and after exercise in health and insulin-dependent diabetes. Exercise and Sport Sciences Reviews, 33(1), 17-23. PMID: 15640716

Cemeroglu, A. P., Thomas, J. P., Zande, L. T., Nguyen, N. T., Wood, M. A., Kleis, L., \& Davis, A. T. (2013). Basal and bolus insulin requirements in children, adolescents, and young adults with type 1 diabetes mellitus on continuous subcutaneous insulin infusion (CSII): Effects of age and puberty. Endocrine Practice, 19(5), 805-811. https://doi.org/10.4158/EP13099.OR

Chiang, J. L., Kirkman, M. S., Laffel, L. M. B., \& Peters, A. L. (2014). Type 1 diabetes through the life span: A position statement of the American Diabetes Association. Diabetes Care, 37(7), 2034-2054. https://doi.org/10.2337/dc14-1140

diaTribe Foundation. (2021). diaTribe Learn. Making sense of diabetes. https://diatribe.org 
Gonder-Frederick, L., Nyer, M., Shepard, J. A., Vajda, K., \& Clarke, W. (2011). Assessing fear of hypoglycemia in children with type 1 diabetes and their parents. Diabetes Management (London, England), 1(6), 627-639. https://doi.org/10.2217/DMT.11.60

Grimm, J. J., Ybarra, J., Berné, C., Muchnick, S., \& Golay, A. (2004). A new table for prevention of hypoglycaemia during physical activity in type 1 diabetic patients. Diabetes \& Metabolism, 30(5), 465-470. https://doi.org/10.1016/s1262-3636(07)70144-1

Harris, G. D., \& White, R. D. (2012). Diabetes in the competitive athlete. Current Sports Medicine Reports, 11(6), 309-315. https://doi.org/10.1249/JSR.0b013e3182751007

Johnson, S. R., Cooper, M. N., Davis, E. A., \& Jones, T. W. (2013). Hypoglycaemia, fear of hypoglycaemia and quality of life in children with type 1 diabetes and their parents. Diabetic Medicine, 30(9), 1126-1131. https://doi.org/10.1111/dme.12247

Kakleas, K., Soldatou, A., Karachaliou, F., \& Karavanaki, K. (2015). Associated autoimmune diseases in children and adolescents with type 1 diabetes mellitus (T1DM). Autoimmunity Reviews, 14(9), 781-797. https://doi.org/10.1016/j.autrev.2015.05.002

Karges, B., Schwandt, A., Heidtmann, B., Kordonouri, O., Binder, E., Schierloh, U., Boettcher, C., Kapellen, T., Rosenbauer, J., \& Holl, R. W. (2017). Association of insulin pump therapy vs insulin injection therapy with severe hypoglycemia, ketoacidosis, and glycemic control among children, adolescents, and young adults with type 1 diabetes. JAMA, 318(14), 1358-1366. https://doi.org/10.1001/jama.2017.13994

Katsarou, A., Gudbjörnsdottir, S., Rawshani, A., Dabelea, D., Bonifacio, E., Anderson, B. J., Jacobsen, L. M., Schatz, D. A., \& Lernmark, A. (2017). Type 1 diabetes mellitus. Nature Reviews. Disease primers, 3: 17016. https://doi.org/10.1038/nrdp.2017.16

Ly, T. T., Nicholas, J. A., Retterath, A., Lim, E. M., Davis, E. A., \& Jones, T. W. (2013). Effect of sensor-augmented insulin pump therapy and automated insulin suspension vs standard insulin pump therapy on hypoglycemia in patients with type 1 diabetes: A randomized clinical trial. JAMA, 310(12), 124-1247.

https://doi.org/10.1001/jama.2013.277818

Marliss, E. B., \& Vranic, M. (2002). Intense exercise has unique effects on both insulin release and its roles in glucoregulation: Implications for diabetes. Diabetes, 51(Suppl 1), S271-S283. https://doi.org/10.2337/diabetes.51.2007.s271

Miller, K. M., Foster, N. C., Beck, R. W., Bergenstal, R. M., DuBose, S. N., DiMeglio, L. A., Maahs, D. M., Tamborlane, W. V., \& T1D Exchange Clinic Network. (2015). Current state of type 1 diabetes treatment in the US: Updated data from the T1D Exchange Clinic Registry. Diabetes Care, 38(6), 971-978. https://doi.org/10.2337/dc15-0078

Naaraayan, S. A., Varadharajan, P., Dhakshayani, R. V., Chandramohan, R., \& Senniappan, S. (2018). Free Style Libre Pro (FSLP) Flash Glucose Monitor (FGM): A novel monitoring tool for children with type 1 diabetes mellitus. Indian Pediatrics, 55(6), 524525. PMID: 29978825

Paternostro Bayles, M., \& Swank, A. M. (2018). ACSM's exercise testing and preparation (7th ed.). Wolters Kluwer.

Patterson, C. C., Karuranga, S., Salpea, P., Saeedi, P., Dahlquist, G., Soltesz, G., \& Ogle, G. D. (2019). Worldwide estimates of incidence, prevalence and mortality of type 1 diabetes in children and adolescents: Results from the International Diabetes Federation Diabetes Atlas, 9th edition. Diabetes Research and Clinical Practice, 157: 107842. https://doi.org/10.1016/j.diabres.2019.107842

Porcellati, F., Lucidi, P., Bolli, G. B., \& Fanelli, C. G. (2013). Thirty years of research on the dawn phenomenon: Lessons to optimize blood glucose control in diabetes. Diabetes Care, 36(12), 3860-3862. https://doi.org/10.2337/dc13-2088

Riddell, M. C., \& Iscoe, K. E. (2006). Physical activity, sport, and pediatric diabetes. Pediatric Diabetes, 7(1), 60-70. https://doi.org/10.1111/j.1399-543X.2006.00146.X 
Riddell, M. C., Bar-Or, O., Hollidge-Horvat, M., Schwarcz, H. P., \& Heigenhauser, G. J. (2000). Glucose ingestion and substrate utilization during exercise in boys with IDDM. Journal of Applied Physiology, 88(4), 1239-1246. https://doi.org/10.1152/jappl.2000.88.4.1239

Roberts, A. J., Taplin, C. E., Isom, S., Divers, J., Saydah, S., Jensen, E. T., Mayer-Davis, E. J., Reid, L. A., Liese, A. D., Dolan, L. M., Dabelea, D., Lawrence, J. M., \& Pihoker, C. (2020). Association between fear of hypoglycemia and physical activity in youth with type 1 diabetes: The SEARCH for diabetes in youth study. Pediatric Diabetes, 21(7), 12771284. https://doi.org/10.1111/pedi.13092

Roberts, A. J., Yi-Frazier, J. P., Aitken, K. E., Mitrovich, C. A., Pascual, M. F., \& Taplin, C. E. (2017). Do youth with type 1 diabetes exercise safely? A focus on patient practices and glycemic outcomes. Pediatric Diabetes, 18(5), 367-375. https://doi.org/10.1111/pedi.12402

Sands, W. A., McNeal, J. R., \& Jemni, M. (2001). Anaerobic power profile: Talent-selected female gymnasts, age 9-12 years. https://usagym.org/pages/home/publications/technique/2001/5/anaerobic.pdf

Santi, E., Tascini, G., Toni, G., Berioli, M. G., \& Esposito, S. (2019). Linear growth in children and adolescents with type 1 diabetes mellitus. International Journal of Environmental Research and Public Health, 16(19): 3677. https://doi.org/10.3390/ijerph16193677

Shugart, C., Jackson, J., \& Fields, K. B. (2010). Diabetes in sports. Sports Health, 2(1), 2938. https://doi.org/10.1177/1941738109347974

Streisand, R., \& Monaghan, M. (2014). Young children with type 1 diabetes: Challenges, research, and future directions. Current Diabetes Reports, 14(9): 520. https://doi.org/10.1007/s11892-014-0520-2

Yardley, J. E., Kenny, G. P., Perkins, B. A., Riddell, M. C., Balaa, N., Malcolm, J., Boulay, P., Khandwala, F., \& Sigal, R. J. (2013). Resistance versus aerobic exercise: Acute effects on glycemia in type 1 diabetes. Diabetes Care, 36(3), 537-542. https://doi.org/10.2337/dc12-0963

Ziegler, R., \& Neu, A. (2011). Diabetes in childhood and adolescence. Aerzteblatt.de International, 115(9), 146-156. https://doi.org/10.3238/arztebl.2018.0146

Ziegler, R., Heidtmann, B., Hilgard, D., Hofer, S., Rosenbauer, J., Holl, R., \& DPV-WissInitiative. (2011). Frequency of SMBG correlates with HbA1c and acute complications in children and adolescents with type 1 diabetes. Pediatric Diabetes, 12(1), 11-17. https://doi.org/10.1111/j.1399-5448.2010.00650.x

Ziegler, R., Rees, C., Jacobs, N., Parkin, C. G., Lyden, M. R., Petersen, B., \& Wagner, R. S. (2016). Frequent use of an automated bolus advisor improves glycemic control in pediatric patients treated with insulin pump therapy: Results of the Bolus Advisor Benefit Evaluation (BABE) study. Pediatric Diabetes, 17(5), 311-318.

https://doi.org/10.1111/pedi.12290 